\title{
Hot Flashes
}

National Cancer Institute

\section{Source}

National Cancer Institute. Hot Flashes. NCI Thesaurus. Code C3109.

A temporary feeling of intense body warmth, flushing, sometimes accompanied by sweating. A common, symptom of menopause; other conditions that can produce hot flushes include antidepressants and drugs blocking the effect of estrogens, carcinoid tumors and a sensitivity to sulfites or other food additives. 